enough penetrating force to pass clean through the side of the strongest ironclad afloat-those of the Hercules class -or, in other words, is endowed with impact sufficient to pierce twelve inches of iron; and it must be remembered that this last-named distance is one at which gunners can make very good practice, so that, under ordinary circumstances, every other shot would take effect against a target such as is presented by the keel of a large frigate. As regards extreme length of range, a quality of some importance, when, as in the recent instance of the Paris siege, great projecting power is of more importance than precision of aim, this Fraser gun may vie with almost any other, with the exception, perhaps, of Whitworth's cannon. The utmost distance to which "the Woolwich infant" as it has been nicknamed, will in all probability be capable of projecting a shell is about ten thousand yards, supposing the arm to be laid at an elevation of some thirty-three degrees.

So satisfactory, indeed, has this experimental structure turned out, that a further batch of sister guns have forthwith been commenced, and will serve to arm some of our heavy iron-clads which are now building. Only a small number of such weapons will be carried by these vessels - two, or at the most four, apiece-and thus our modern men-of-war will present a perfect contrast to those of a clozen years ago, when a ship, being regarded merely as a box of guns, sometimes received on board as many as a hundred and thirty cannon. Nevertheless, a broadside delivered from four guns of these giant dimensions (for the whole armament being carried in turrets may be brought to bear at one time), representing almost a ton and a half of metal, very far exceeds that which an old first-class three-decker could throw into her antagonist, and would indeed be sufficient to sink most vessels at a first discharge.

As regards the method of building up these large guns, we noed say nothing, seeing that the subject was fully discussed recently in these columns. It may be of interest to know, however, that in the present instance as much as fifty tons of metal were employed in constructing the arm, and that at one time thirty tons of this was brought to a glowing white heat for the purpose of welding. 'The reverberatory furnace in which this massive coil was heated is an apartment in which a dozen persons could dine comfortably, and the length of the bars before coiling amounted to upwards of $I, 200$ feet. The length of the arm is sixtcen feet and a quarter, and its extreme diameter fifty-six inches.

\section{A NEW INEXTINGUISHABLE STORM AND DANGER SIGNAL LIGHT}

THIS new Signal, possessing most remarkable properties, has now been brought before the public. It was first exhibited at the President's meeting of the Royal Society on 22nd April, when it attracted great attention. The peculiarities of the Signal Light are, that it is self-igniting when placed in water or thrown on the sea. Contact with water being the only means of igniting the lamp, it is inextinguishable when once ignited; neither wind nor storm has any effect upon the flame. The light is of intense brilliancy, and of great duration, and can be seen for a great distance in the open-air. Photographs may be taken by the light of this new signal. Experiments were tried on the evening of 25 th April, at ten o'clock, in the presence of some scientific gentlemen, to determine its brilliancy as a signal. A lamp was placed in a bucket of water on the top of Primrose Hill, and the light was so intense that after the signal had been burning for twenty minutes small newspaper-print could be distinctly read at a distance of seventy feet, notwithstanding that the night was thick and foggy. This new signal light will burn for over forty minutes. In construction the lamp is exceedingly simple, and so contrived that when once burnt the whole may be thrown away. The chemical preparation contained in the lamp is a solid, hard substance, free from danger ; not affected by heat, and so non-explosive; and the signal is comparatively inexpensive. Its applications for marine signals are numerous. In case of shipwreck a few lamps thrown on the sea would illuminate the entire scene, and enable assistance to be promptly and efficiently rendered. For rocket-line apparatus it is equally valuable, as, bursting into a frame on falling into the sea, it would indicate the position of the rocket-line. In connection with life buoys it would be a mark to the drowning sailor. In life-boat services it would be a signal to the vessel in distress, and the brilliant light would greatly assist in the rescue. In cases of salvage, ships' signals, tide and harbour warnings, the duration of the light renders this new invention of great value. As a railway signal, to be used by the guards and station porters in cases of accident, it is equally available, and will be of great utility. The difficulties of preparing the chemical compound have been entirely overcome by Messrs. Albright and Wilson, of Oldbury, the contractors for the manufacture of the lamp for $M r_{\text {; }}$ Nathaniel Holmes the patentee.

\section{FRESHWATER BATHYBIUS}

$A T$ a late meeting of the Natural History and Medical A Society of the Lower Rhine, the well-known zoologist, Dr. R. Greeff, noticed an organism inhabiting freshwater and approaching very nearly, both in its structure and mode of occurrence, the celebrated deep-sea, Bathybizs Hackeliz of Professor Huxley.

Dr. Greeff, as much as three years ago, published a notice (in Max Schultze's "Archiv fiir mikrosk. Anat." Bd. iii., p. 396) of a new shell-less freshwater Rhizopod, which was remarkable for its gigantic stature in com parison with all previously-known organisms of that kind. Hecalled attention at that time to its occasional occurrence in great quantity in the mud of standing waters, and indicated that, on account of its peculiar structure, it could be referred rieither to the true Amaba nor to the Actinophryes. Since that time, the author has never lost sight of this extremely remarkable creature, and he thinks it desirable no longer to keep back his observations, especially considering the high degree of interest that has been excited by the Bathybius-mud which has been discovered in the depths and abysses of the ocean (to beyond 25,000 feet).

As regards the occurrence of this freshwater organism, to which the author provisionally gives the name of Pelobizus, and which he considers to be truly comparable with Bathybizts, Dr. Greeff states that it is found in many standing waters with muddy bottom, which have apparently persisted for a long time, and seldom, if ever, have dried up. Thus, near Bonn the bottom of the Poppelsdorf fish-pond is found occasionally to be almost entirely covered with masses of Pelobius; to such an extent, indeed, that sometimes a glass vessel brought up from the bottom contains almost more Pelobius than true mud-particles, \&c. The Pelobuzus never disappears in these waters, but remains throughout the year in great masses, sometimes in one place, sometimes in another. The cake-like lumps of mud which rise to the surface and float about there by the agency of enclosed gas and air-bubbles, especially during the warm season, also sometimes contain Pelobizs in masses.

In their external form, in both the living and the contracted state, these organisms present the appearance of more or less spherical lumps, varying from one or two millim. in diameter down to the most minute points, scarcely perceptible by the naked eye, Middle-sized ED.]] 